\title{
Perceived Barriers to Uptake of Cervical Cancer Screening Among Women of Childbearing Age in a Gynaecological Clinic
}

\author{
Adebusola T. Amos ${ }^{1} \quad$ Olutosin A. Awolude ${ }^{2 *}$ \\ 1.Clinical Nursing Services Department, University College Hospital, Ibadan, Nigeria \\ 2.Obstetrics and Gynaecology, College of Medicine, University of Ibadan/University College Hospital, Ibadan, \\ Nigeria
}

\begin{abstract}
Introduction

Cervical cancer is an important reproductive health problem for women in the developing countries where it constitutes $13 \%$ of all female malignancies. It is the second most common cancer in women worldwide and 83 percent of the world's 500,000 new cases and 85 percent of the 288,000 cervical cancer deaths occur in developing countries. Evidences show that women attending various health facilities were not routinely screened for cervical cancer. Gynaecological clinics present an important access to target group for cervical cancer screening. This study assessed the barriers to uptake of cervical cancer screening services among women attending a gynaecological clinic of a tertiary health i a tertiary health facility in South West region of Nigeria, the most populous black country of the world.

Methodology

Adopting a descriptive cross-sectional approach and Health Belief Model (HBM), women aged 15 - 49 years attending gynaecological clinic at the health institution were interviewed. The respondents were selected using systematic random sampling technique and interviewed using a specially designed structured questionnaire. Barrier to uptake of cervical cancer screening services was defined as significant when the number of the respondents in the "agree" and "strongly agree" domains to the selected reasons for not screening for cervical cancer are at least $50 \%$.

Results

Of the 100 respondents interviewed, 85 responses were found suitable for analysis. The mean age of the respondents was $33.3(\mathrm{SD} \pm 8.6)$ years. Although a large proportion of the respondents $(77.1 \%)$ were aware of cervical cancer, $95.2 \%$ with at least secondary education and $51.9 \%$ earning at least $\$ 50,000 /$ month, only 23 (27.1\%) had undergone the screening for cervical cancer. Age $>44$ years and earning $>100,000 /$ month were positively and significantly associated with uptake of cervical cancer screening. The significant reasons for not screening for cervical cancer by the respondents were Lack of information/counselling (77.4\%), Lack of convenient clinic time (62.9\%), Fear of having a positive result (61.3\%), Lack of support from partners and significant others is a barrier (56.5\%) and Attitude of health workers discourage women from assessing cervical cancer screening $(51.6 \%)$

\section{Conclusion}

It can be concluded from this this study that there is need for need for regular information on cervical screening at every opportunity for the populations that will benefit from this preventive service like women of reproductive age group attending our obstetric services. There is an urgent need for provision of more screening opportunities especially the type that will have population coverage and to leverage on other programmes like family planning services, post-natal clinic services and HIV/AIDS programmes. Screening services should be available in all secondary facilities and primary health care centres. Reminder/Recall services should be in place to ensure compliance with appointments in order to increase utilization
\end{abstract}

Keywords: Perceived Barriers, Uptake, Women of childbearing age, Cervical Cancer screening

DOI: $10.7176 / \mathrm{JHMN} / 67-07$

Publication date:October $31^{\text {st }} 2019$

\section{Introduction}

Cervical cancer is an important reproductive health problem for women in the developing countries where it is a common gynaecological malignancy. It is the second most common cancer in women worldwide, with 500,000 new cases and 288,000 deaths estimated to have occurred worldwide annually. (American Cancer Society, 2010). Women of less resource countries are mostly affected with this condition as it is reported that $83 \%$ of the world's new cases and $85 \%$ of all cervical cancer deaths occur in developing countries. (Saonere, 2010, American Cancer Society, 2015). It is a social problem as this condition affects not only the health and lives of the women, but also their children, families, and their communities at large. It affects women in both premenopausal and postmenopausal years.

In Nigeria, the national incidence of cervical cancer is 250/100,000 (Oguntayo et al., 2011) and was reported as the leading cause of gynaecological cancers in North-West Nigeria, accounting for $65.7 \%$ of all gynaecological 
cancers. This high mortality rate was also observed in Ibadan, South-West and Maiduguri, North-East, Nigeria with $62.7 \%$ and $72.6 \%$ respectively (Pindiga et al., 2009).

This grim picture contrasts sharply with what is obtained in developed countries where the incidence and mortality are about half for the rest of world. The huge disparities in morbidity and mortality between developed and developing countries exist largely because over the last few decades, developed countries have implemented effective, population-based programmes for the prevention of cervical cancer reducing the incidence and mortality by up to $80 \%$ (Sankaranarayanan et al., 2001). On the other hand, in developing countries where access to screening services for cervical cancer is often limited or non-existent, the incidence of women affected by the disease continues to exist at high levels (Vizcaino et al., 2000, Wabinga et al., 2000).

Prevention of cervical cancer has been extensively studied to reduce or eliminate the occurrence of this preventable disease and its negative impacts. Despite these, findings revealed that many women still do not participate in cervical cancer prevention programmes. The prevalence and cervical cancer-related deaths remain high and are increasing in developing countries. Over the years, studies in our environment have repeatedly revealed poor awareness and uptake of services directed towards cervical cancer screening. For example, in SouthEast city of Owerri, Imo state, Nigeria, despite lack of awareness as the main reason for women not attending screening clinics (Ezem BU, 2007), increased awareness may not translate to increased utilization, as healthcare workers, medical students and physicians who have a high level of awareness demonstrated a low level of utilization (Ayinde, et.al, 2004, Cyril, et.al, 2009). Other barriers include ignorance about cervical cancer, cultural constraint or beliefs about illness, socio-economic factors, alternative authoritative sources of reproductive health knowledge and unfriendly health care services. (Mutyaba, et.al, 2007). Hence, identifying and understanding the barriers that limits the uptake of cervical cancer screening programmes in the community can be used to enhance the participation rates of women in prevention programs that can be organized by health workers in the future. This study focused on the perceived barriers to the awareness and uptake of cervical cancer screening services amongst women of childbearing age attending the gynaecological outpatient clinic of University College Hospital, Ibadan. The findings from this study, we hope, will also add to existing body of knowledge about barriers to uptake of cervical cancer screening in Nigeria and proffer possible suggestions for overcoming these barriers.

\section{Methodology \\ Study Design}

This is a descriptive cross-sectional study to assess the perceived barriers to the uptake of cervical cancer screening among women of childbearing age attending the gynaecological clinic at University College Hospital, Ibadan.

\section{Study Setting}

The study was carried out at the e gynaecological outpatient clinic of the University College Hospital Ibadan, Oyo State. Ibadan, the capital of Oyo state located in the western region of Nigeria, is made up of eleven (11) local governments, consisting of five urban local governments and six semi-urban local governments, with a population of 3.2 million. The University College Hospital is located in Ibadan North local government area. It was established by an act of parliament in November of 1952 as the first Teaching Hospital in Nigeria. It serves as a referral centre for hospitals in the neighbouring states. The physical development of the hospital commenced in 1953 in its present site and was formally commissioned after completion on $20^{\text {th }}$ November 1957 . The hospital and the University of Ibadan function in excellent symbiosis in health manpower training, research and clinical service. The hospital has 1,220 bed spaces. It is a tertiary institution with appendages of community-based outreach activities with 56 service and clinical department and 96 consultative outpatient clinics in 50 specialities and sub specialities.

\section{Study Population}

The study population were women aged 15-49years attending the gynaecological outpatient clinic of the University College Hospital Ibadan who consented to be part of the study. These formed the accessible population and a representative of the target population. The gynaecological outpatient clinics of the hospital runs 3 times a week on Mondays, Tuesdays and Thursdays between the hours of 12 noon and 6pm.

\section{Sampling Technique}

Systematic random sampling technique was used for selection of the respondents. The included participants were all consenting women aged 15-49 years attending the outpatient gynaecological clinic of University College Hospital, Ibadan. The first respondent at each clinic day was selected randomly from the list of eligible respondents among the patients presenting to the clinic for the day while the remaining respondents were every subsequent third patient from the list to reduce bias and ensure representativeness. This process was repeated each day until the sample size of 100 respondents for the study was reached. A specially designed structured questionnaire divided into four sections was used for data collection. Section (A) included demographic data of respondents; Section (B) was on the knowledge of the respondents of cervical cancer; Section (C) was on the awareness of cervical cancer screening programmes; and Section (D) was on the perceived barriers to cervical cancer screening. A copy of the questionnaire was reviewed by the authors and other experts in the field of the study for both content and faces validity; the content was corrected as required. A test-retest method was used to determine the reliability 
of the instrument as copies of the questionnaires were administered to 15 women of childbearing age attending the gynaecological clinic of a secondary health care centre in the city. The same was given back to the respondents after two weeks. The reliability was determined by comparing the two results. The study was approved by Ethical Review Board of UI/UCH. Written informed consent for the study was obtained from the participants before inclusion into the study.

\section{Data Analysis}

The data from the questionnaires were entered into a spread-sheet. Categorical data were recorded into numerical variables. Statistical analysis was performed using Statistical Package for Social Sciences (SPSS) version 21.0 for Windows. The results were presented using descriptive statistics. Frequency tables, percentages and graphical representation was also used to present the findings. Univariate analyses using frequency distribution and means was carried out to describe the characteristics of the respondents. An independent t-test was conducted to determine if there is a significant difference between the studied parameter. Chi square was used to test for association between variables. All tests were analysed with a confidence interval of $\alpha=0.05$. The level of statistical significance ( $\mathrm{p}$ level) was set at $\leq 0.05$.

\section{Results}

A total of 85 of the 100 questionnaires administered to respondents attending gynaecology outpatient clinic at the University College Hospital, Ibadan data were found suitable for analysis for this study.

\section{Socio-demographic Characteristics of the Respondents.}

The mean age of the respondents was $33.3 \pm 8.6$ years. About $72 \%$ were married and of Yoruba tribe while more than $80 \%$ were Christians and lived in Urban areas. More than three-quarter had tertiary education while 45-49 \% were involved in skilled occupation and earned between ten and fifty thousand naira per month (Table 1).

\section{Table 1: Socio-demographic Characteristics of the Respondents.}

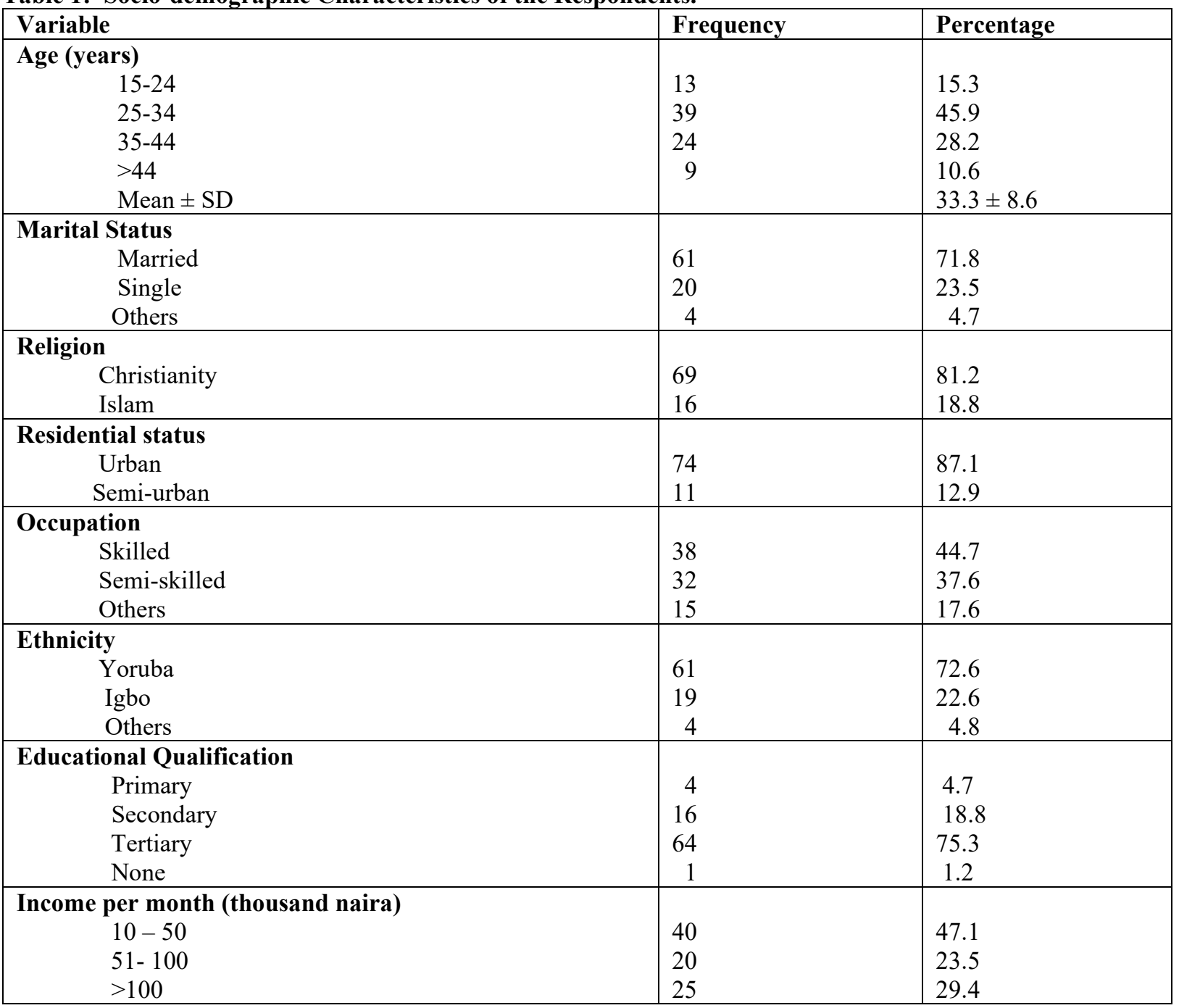


Awareness of cervical cancer, methods of screening and knowledge of methods of prevention.

Seventy-seven percent of the respondents have heard about cervical cancer and $80 \%$ have heard about cervical cancer screening programmes. The major sources of information were health professional (46.8\%), mass media $(21.1 \%)$ and public lecture (11.9\%). Knowledge of cervical cancer and its methods of prevention were low among the respondents. The mean knowledge score was 5.0 which is less than the average rating score of $6.0(50 \%$ of the total score of 12$)$. Only $23(27.1 \%)$ had availed themselves of cervical prevention servicesand the prevention methods used were Pap smear $(n=20,87.0 \%)$ and HPV Vaccination $(n=3,13.0 \%)$. Major risk factors for cervical cancer stated by the respondents include smoking (36.8\%), early exposure to sexual intercourse $(29.8 \%)$ and sexually transmitted infections $(33.4 \%)$. Sixty-six percent of the respondents agreed cervical cancer is curable if detected early and 78.3\% knew that cervical cancer can be prevented. Major methods of prevention known by the women were screening, 55.8\% [Conventional cytology, 39.5\%; Visual Inspection with application of Acetic Acid, 9.3\%; Liquid based cytology, 7\%], HPV Vaccination, $27.1 \%$ and behavioural modifications like safe sex practice, $17.1 \%$.

Table 2: Awareness of cervical cancer and methods of screening.

\begin{tabular}{|c|c|c|}
\hline Variable & Frequency & Percentage \\
\hline Have you heard about cervical cancer? & 66 & 77.6 \\
Yes & 19 & 22.4 \\
No & & \\
Have you heard about cervical cancer screening? & 67 & 78.8 \\
Yes & 15 & 17.6 \\
Not sure & 3 & 3.5 \\
\hline Health professional & 51 & 46.8 \\
Mass media & 23 & 21.1 \\
Public lecture & 13 & 11.9 \\
Friends/relations & 10 & 9.2 \\
School & 12 & 11.0 \\
\hline know, what are your sources? & & \\
Yes & 64 & 75.3 \\
No & 13 & 15.3 \\
Not sure & 8 & 9.4 \\
\hline Yes & & \\
No & 23 & 27.1 \\
Not sure & 60 & 70.6 \\
Pap smear & 2 & 2.4 \\
\hline Hav Vaccination & 20 & \\
\hline
\end{tabular}

$\alpha=$ multiple responses allowed

\section{Factors Influencing Uptake of Cervical Cancer Screening}

Based on the perception of the respondents, the major barriers to the uptake of cervical cancer screening are lack of information/counselling (77.4\%), fear of having positive results $(61.3 \%)$, lack of support from partners and significant others $(56.5 \%)$, lack of convenient clinic time $(62.9 \%)$ and attitude of health workers $(51.6 \%)$.

As shown in the Table 3, knowledge of cervical cancer was higher among those who have had cervical cancer screening $(5.83 \pm 3.04)$ than those who have not $(4.69 \pm 3.47)$ although there was no significant difference in knowledge between the groups $(p=0.17)$. From the study only age $>44$ years and income $>$ N100, 000 were significantly and positively associated with uptake of cervical cancer screening among the studied population. Other socio-demographic characteristics such as marital status, religion, occupation, residential status, ethnicity and educational qualification were not significantly associated with uptake of cervical screening among the women. Of all the socio-demographic characteristics, only age $(\mathrm{p}<0.001)$, occupation $(\mathrm{p}<0.001)$, and income $(\mathrm{p}=0.01)$ were significant predictors of the knowledge of cervical cancer and its prevention programmes. Others such as marital status $(\mathrm{p}=0.43)$, religion $(\mathrm{p}=0.86)$ residential status $(\mathrm{p}=0.15)$, ethnicity $(\mathrm{p}=0.18)$, and education $(\mathrm{p}=$ 0.11 ) were not significant predictors of the dependent variable (Table 4). 
Table 3: Barriers to Uptake of Cervical Cancer Screening

\begin{tabular}{|c|c|c|c|c|}
\hline & $\begin{array}{l}\text { A } \\
(\%)\end{array}$ & $\begin{array}{l}\text { SA } \\
(\%)\end{array}$ & $\begin{array}{ll}\text { A } & + \\
\text { SA }\end{array}$ & $\%$ \\
\hline Lack of information/counselling & 25 & 23 & 48 & 77.4 \\
\hline Cervical cancer screening is embarrassing & 18 & 4 & 22 & 35.5 \\
\hline Cervical cancer screening is painful & 13 & 8 & 21 & 33.9 \\
\hline Fear of having a positive result. & 29 & 9 & 38 & 61.3 \\
\hline Only women with STIs should go for cervical cancer screening. & 11 & 3 & 14 & 22.6 \\
\hline Cervical cancer screening is not available in all health facilities & 16 & 6 & 22 & 35.5 \\
\hline Cervical cancer screening is not affordable & 15 & 7 & 22 & 35.5 \\
\hline Lack of female health screeners in health facilities is a barrier & 21 & 8 & 29 & 46.8 \\
\hline $\begin{array}{l}\text { Attitude of health workers discourage women from assessing cervical } \\
\text { cancer screening. }\end{array}$ & 24 & 8 & 32 & 51.6 \\
\hline Lack of support from partners and significant others is a barrier & 26 & 9 & 35 & 56.5 \\
\hline Lack of convenient clinic time is a barrier & 28 & 11 & 39 & 62.9 \\
\hline
\end{tabular}

$\mathrm{A}=$ agree, $\mathrm{SA}=$ strongly agree, $\mathrm{NS}=$ Not sure, $\mathrm{D}=$ disagree, $\mathrm{SD}=$ Strongly disagree

Table 4: Determinants of cervical cancer screening uptake

\begin{tabular}{|c|c|c|c|}
\hline \multirow[t]{2}{*}{ Variable } & \multicolumn{2}{|c|}{ Uptake of cervical cancer screening } & \multirow[t]{2}{*}{ p-value } \\
\hline & No & Yes & \\
\hline Knowledge & $4.69 \pm 3.47$ & $5.83 \pm 3.04$ & 0.17 \\
\hline $\begin{array}{l}\text { Age } \\
15-24 \\
25-34 \\
35-44 \\
>44\end{array}$ & $\begin{array}{l}12(92.3) \\
32(82.1) \\
14(58.3) \\
4(44.4)\end{array}$ & $\begin{array}{l}1(7.7) \\
7(17.9) \\
10(41.7) \\
5(55.6)\end{array}$ & $<0.001$ \\
\hline $\begin{array}{l}\text { Marital Status } \\
\text { Married } \\
\text { Single } \\
\text { Others }\end{array}$ & $\begin{array}{l}43(70.5) \\
16(80.0) \\
3(75.0)\end{array}$ & $\begin{array}{l}18(29.5) \\
4(20.0) \\
1(25.0)\end{array}$ & 0.43 \\
\hline $\begin{array}{l}\text { Religion } \\
\text { Christianity } \\
\text { Islam } \\
\end{array}$ & $\begin{array}{l}48(70.6) \\
14(87.5)\end{array}$ & $\begin{array}{c}20(29.4) \\
2(12.5)\end{array}$ & 0.18 \\
\hline $\begin{array}{l}\text { Residential status } \\
\text { Urban } \\
\text { Rural }\end{array}$ & $\begin{array}{c}53(71.6) \\
7(77.8)\end{array}$ & $\begin{array}{c}21(28.4) \\
2(22.2)\end{array}$ & 0.11 \\
\hline $\begin{array}{l}\text { Occupation } \\
\text { Skilled } \\
\text { Semi-skilled } \\
\text { Others } \\
\end{array}$ & $\begin{array}{l}24(63.2) \\
24(75.0) \\
14(93.3)\end{array}$ & $\begin{array}{c}14(36.8) \\
8(25.0) \\
1(6.7)\end{array}$ & 0.01 \\
\hline $\begin{array}{l}\text { Ethnicity } \\
\text { Yoruba } \\
\text { Igbo } \\
\text { Others }\end{array}$ & $\begin{array}{l}43(70.5) \\
14(73.7) \\
4(100.0)\end{array}$ & $\begin{array}{l}18(29.5) \\
5(26.3) \\
0(0.0)\end{array}$ & 0.18 \\
\hline $\begin{array}{l}\text { Educational Qualification } \\
\text { Secondary or less } \\
\text { Tertiary }\end{array}$ & $\begin{array}{l}15(75.0) \\
47(73.4)\end{array}$ & $\begin{array}{c}5(25.0) \\
17(26.6)\end{array}$ & 0.11 \\
\hline $\begin{array}{l}\text { Income per month(thousand) } \\
10-50 \\
51-100 \\
>100\end{array}$ & $\begin{array}{l}33(86.8) \\
11(61.1) \\
13(56.5)\end{array}$ & $\begin{array}{c}5(13.2) \\
7(38.9) \\
10(43.5)\end{array}$ & 0.01 \\
\hline
\end{tabular}

\section{Discussion}

At every stage in life, women in the less resourced countries risk some serious health problems including human immunodeficiency virus/acquired immune deficiency syndrome (HIV/AIDS), high maternal mortality ratios and cancer of the cervix (Ezem, 2007). In recent times, there appears to be a surge in non-communicable diseases as has been seen in the last few decades in the developed world. Cervical cancer, an easily preventable disease, is prominent amongst them. This study examined the theoretical construct of perceived barrier, of health belief model, 
to the uptake of cervical cancer screening services among eligible participants in a gynaecolocal out-patients service.

All respondents in this study were women of childbearing age and were sexually active, thus at risk of infection with HPV, the causative agent for cervical cancer. They have access to modern health care facilities. Majority of the women were aged 34 years or younger and married, but were mainly traders, and earned between 10,000 - 50, 000 naira per month making them, significantly, economically dependent. In this study, $77.1 \%$ of respondents were aware of cervical cancer as they have heard about it. Similar high levels of awareness were observed in the study carried out among nurses at the Lagos University Teaching Hospital (LUTH) Nigeria, where $99 \%$ of their respondents were aware of the disease (Awodele et al., 2011). This high level of awareness observed in our study was not unexpected considering the educational background of the respondents. Eighty of the participants $(94.1 \%)$ had at least secondary education. However, the high level of awareness observed in this study contrasts with the findings from similar studies carried out in Maiduguri and Abuja, Nigeria where less than 10\% of their respondents were aware of the disease (Audu et al., 1999; Nnodu et al., 2010). A study among women attending gynaecology clinics in a tertiary level medical care centre in South Eastern Nigeria affirmed that, twentyfive $(12.6 \%)$ of the women were aware of the cervical cancer screening test (Mbamara, 2011). (Reasons)A greater proportion of our respondents got information about cervical cancer through health professionals and mass media. This agrees with findings from Lagos, Nigeria, where most of their subjects got information regarding the disease from the electronic media (Awodele et al., 2011).

The respondents in our study had a poor knowledge of cervical cancer and its prevention methods. This is similar when compared with findings from other parts of Nigeria (Awodele et al., 2011; Nnodu et al., 2010; Oyedunni and Opemibo, 2012). About $40 \%$ of the subjects were aware of Pap smear as one of the screening procedures for cervical cancer.

The high level of awareness of cervical cancer demonstrated by our subjects did not translate to proper utilization of the screening procedure. Although a greater proportion of our subjects $(77.1 \%)$ were aware of the disease, only $23(27.1 \%)$ of the respondents had undergone the screening for cervical cancer. This poor utilization of the screening services observed in our study affirms similar findings in studies in Nigeria ( Udigwe, 2006; Ayinde et al., 2004; Ezem, 2007) and other parts of the world (Mutyaba et al., 2006; Lyimo and Beran, 2012).

Major reasons given for not undergoing the screening test for cervical cancer by our respondents included fear of pain, fear of outcome of the test and lack of awareness. These findings are in consonance with other studies in Nigeria (Udigwe, 2006; Oyedunni and Opemibo, 2012). Other barriers include lack of support from partners and significant others (57.2\%), lack of convenient clinic time (63.9\%) and attitude of health workers $(52.4 \%)$. Lack of support and encouragement from close family members like husbands and friends ((Al-Naggar et al., 2010; Oon et al., 2011)), health care professionals ((Hewitt et al., 2004; Wong et al., 2009; Al-Naggar et al., 2010, Othman and Rebolj, 2009)) are important barriers to women attending cervical cancer screening. The cost of attending clinics in terms of travel and lost time (Oon et al., 2011) and fee for screening (Hewitt et al., 2004) are other economic barriers. Hence, Government intervention by way of provision of subsidies (Abotchie and Shokar, 2009; Al-Naggar et al., 2010), inclusion of routine cervical cancer screening in the health insurance scheme (Mupepi et al., 2011). will impact positively on cervical screening uptake. In our setting as the cost of prevention is insignificant compared to the considerable financial burden of treating cervical cancer patients.

While this study has brought the significance of barrier as health belief model in the successful implementation of cervical cancer screening in our setting, this might be a tip of the iceberg as other components of health belief model theoretical construct of perceptions of seriousness of cervical cancer, susceptibility to the disease and benefits of screening were not tested in this study. There is, therefore the need to carry out a larger study testing the full components of the health belief model (HBM) along with its modifying variables such as culture, past experiences, motivations, etc and cues to the actions which are events, people or things that move people to change their behaviour and health seeking practices. Example relevant to this study will be events like cervical cancer is a family member.

The discordance between the level of awareness and practice of this useful prevention service needs to be bridged. Information on cervical screening should be given regularly to women at every available opportunity supported with the friendly environment for service uptake in term of inftrastructure, attitude and removal of economic bottlenecks. There is urgent need for nationally appropriate screening programme at all levels of health care for universal coverage. There is need for development of policy and framework on health screening. Reminder/Recall services, which can be mobile telecommunication based, should be in place to ensure compliance with appointments to increase utilization in this era of access to cell phones.

Competing interests: Authors did not have any conflict of interest Authors' contributions:

1: Adebusola T. Amos, RN, BNSc, conceived the idea, development of the proposal, involved in data collection, entry, analysis and manuscript writing. 
2: Olutosin A. Awolude, MBBS, MSc, FWACS, involved in proposal development, data collection, analysis and manuscript writing.

\section{Authors' information:}

1: Adebusola T. Amos, RN, BNSc, Senior Nursing Officer, University College Hospital, Ibadan, Nigeria

2. Olutosin A. Awolude, MBBS, MSc, FWACS, Senior Lecturer/Consultant, Department of Obstetrics and Gynaecology, College of Medicine, University of Ibadan/University College Hospital, Ibadan, Nigeria

\section{Acknowledgements:}

We wish to acknowledge the guidance of Dr. Adenike C. Onibokun of Department of Nursing, University of Ibadan for her guidance during the study, the administration of University College Hospital, Ibadan, Nigeria who allowed us access to the patients and the facility. We would also like to acknowledge the Research assistants who helped in extraction and recording of the data.

\section{REFERENCES}

American Cancer Society. (2010). Screening Guidelines for the Prevention and Early Detection of Cervical Cancer American Cancer Society, Atlanta, Ga.

Agurto I, Bishop A, Sanchez G, Betancourt Z, Robles S. (2004). Perceived barriers and Benefits to cervical cancer screening in Latin America. Prev Med 39:91-98.

Airede L.R, Onakewhor J.U.E, Aziken M.E, Ande A.B.A, Aligbe J.U. (2008). Carcinoma of the Uterine Cervix in Nigerian Women: The Need to Adopt a National Prevention Strategy. Sahel Medical Journal 11(1):1-11.

Al Sairafi, M. and. Mohamed F.A. (2009). Knowledge, attitudes, and practice related to cervical cancer screening among Kuwaiti women. Medical Principles and Practice, 18(1): 35-42.

Al-Naggar, R.A, Low W and Isa Z.M. (2010). Knowledge and barriers towards cervical cancer screening among young women in Malaysia. Asian Pacific Journal of Cancer, 11(4): 867-873.

American Cancer Society. (2015.) Cervical cancer prevention in the $21^{\text {st }}$ century. www.cancer.org.com

Austin, L.T. Ahmad, F. McNall, M.J and Stewart D.E. (2002). Breast and cervical cancer screening in Hispanic women: A literature review using the health belief model. Women's health issues. Journal of Women's Health, 12(3): 122.

Ayinde, O.A. Omigbodun, A.O. Ilesanmi, A.O. (2004) Awareness of cervical cancer, Papanicolaou smear and its utilisation among female undergraduates in Ibadan. African Journal of Reproductive Health 8: 68-80.

Bosch F.X and Munoz N. (2006). The viral aetiology of cervical cancer. Virus Research journal, 89: 183-190

Blanche B.E (2009). Intraepithelial and invasive carcinoma of the cervix in clinical cytotechnology. Coleman DV, Chapman PA, eds. London: Butterworths: 195-219

Cyril C. Dim Ekwe, E. Madubuko, T. Ngozi, R. Dim Hyginus U. Ezegwui (2009) Improved awareness of Pap smear may not affect its use in Nigeria: a case study of female medical practitioners in Enugu, south-eastern Nigeria. Royal Society of Tropical Medicine and Hygiene.2009;103(8)852

Byrd, T.L., S.K. Peterson, R. Chavez and A. Heckert, (2004). Cervical cancer screening beliefs among young Hispanic women. Journal of preventive Medicine, 38(2): 192-197.

Cannistra S.A and Niloff J.M (2006). Cancer of the uterine cervix. England Journal of Medicine; 334: 1030-1038

Ezem BU. (2007). Awareness and uptake of cervical cancer screening in Owerri, South- Eastern Nigeria. Ann Afr Med. 2007 Sep;6(3):94-8.

Farooqui, M, Hassali M.A, Knight A, Shafie A.A, Farooqui M.A, Saleem, M, Haq N.U and Aljadhey H, (2013) A qualitative exploration of Malaysian cancer patients' perceptions of cancer screening. BMC journal of public health, 13(1): 48.

Glanz K, Lewis F.M, Rimer B. (2002). Health behaviour and health education: Theory research and practice. San Francisco: 52.

Glanz, K. and B.K. Rimer, (2002). Theory at a glance: A guide for health promotion practice. US Department of Health and Human Services. National Cancer Institute.

Guvenc, G, Akyuz A and Açikel C. (2011). Health belief model scale for cervical cancer and Pap smear test: Psychometric testing. Journal of Advanced Nursing, 67(2): 428-437.

Ibekwe, C, Hoque M and Ntuli-Ngcobo B. (2011). Perceived barriers of cervical cancer screening among women attending Mahalapye district hospital, Botswana. Archives of clinical microbiology, 2(1).

Janz, N.K. and M.H. Becker, 1984. The health belief model: A decade later. Health Education \& Behaviour, 11(1): $1-47$.

Kwok, C, White, K and Roydhouse J.K. (2011). Chinese-Australian women's knowledge, facilitators and barriers related to cervical cancer screening: A qualitative study. Journal of Immigrant and Minority Health, 13(6): 1076-1083.

Lovell, S. Kearns, R.A and Friesen W. (2007). Socio-cultural barriers to cervical screening in south Auckland, New Zealand. Journal of social science \& medicine, 65(1): 138-150.

Monga, A.K. Campbell, S. (2000). Premalignant and malignant disease of the cervix uteri. Gynaecology by Ten 
Teachers 17 ed. London: Arnold.

Mutyaba, T, Faxelid, E. Mirembe F and Weiderpass E. (2007). Influences on uptake of reproductive health services in Nsangi community of Uganda and their implications for cervical cancer screening. Journal of reproductive health, 26 (4): 4

Ogedegbe, G. Cassells, A.N. Robinson, C.M. Duhamel K. Tobin, J.N. Sox, C.H and Dietrich, A.J. (2005). Perceptions of barriers and facilitators of cancer early detection among low-income minority women in community health centres. Journal of the National Medical Association, 97(2): 162.

Oon, S.W. Shuib, R. Ali, S.H. Hussain N.H.N, J. Shaaban J and Yusoff, H.M. (2011). Factors affecting health seeking behaviour among kelantanese women on pap smear screening.

Redhwan, A.N. (2012). Practice and barriers towards cervical cancer screening among university staff at a Malaysian university. Journal of Community Medicine \& Health Education.

Roblyer D, Richards-Kortum R, Park S.Y. Adewole, I. Follen, M. (2007). Objective screening for cervical cancer in developing nations: Lessons from Nigeria. Gynaecology Oncology journal. 107: 94-97

Rosenstock, I.M. Strecher, V.J. Becker, M.H. (1988). Health Belief Model and preventive health behaviour. Health Education monographs; 2:354-386.

Sankaranarayanan R. (2006). Evidence base: implications for policy and practice. World Health Organization, International Agency for Research on Cancer. http://www.alliance-cxca.org

Saonere, A. J. (2010). Awareness screening programs reduces the risk of cervical cancer in women. African Journal of Pharmacy and Pharmacology; 4(6): 314-23.

Twinn, S. and Cheng F. (2001). Increasing uptake rates of cervical cancer screening amongst Hong Kong Chinese women: The role of the practitioner. Journal of Advanced Nursing, 32(2): 335-342. 